\title{
Strengths and Failure Characteristics of Self-Compacting Concrete Containing Recycled Waste Glass Aggregate
}

\author{
Rahman Khaleel AL-Bawi, ${ }^{1,2}$ Ihsan Taha Kadhim, ${ }^{1,3}$ and Osamah AL-Kerttani ${ }^{1,4}$ \\ ${ }^{1}$ Department of Civil Engineering, Gaziantep University, 27310 Gaziantep, Turkey \\ ${ }^{2}$ Civil Engineering Department, Diyala University, Diyala, Iraq \\ ${ }^{3}$ Building and Construction Department, University of Technology, Baghdad, Iraq \\ ${ }^{4}$ Civil Engineering Department, Al-Mustansiriyah University, Baghdad, Iraq
}

Correspondence should be addressed to Ihsan Taha Kadhim; ihsantahak@yahoo.com

Received 18 May 2017; Revised 8 July 2017; Accepted 18 July 2017; Published 17 August 2017

Academic Editor: Tung-Chai Ling

Copyright (C) 2017 Rahman Khaleel AL-Bawi et al. This is an open access article distributed under the Creative Commons Attribution License, which permits unrestricted use, distribution, and reproduction in any medium, provided the original work is properly cited.

\begin{abstract}
The effects of different proportions of green-colored waste glass (WG) cullet on the mechanical and fracture properties of selfcompacting concrete (SCC) were experimentally investigated. Waste bottles were collected, washed, crushed, and sieved to prepare the cullet used in this study. Cullet was incorporated at different percentages $(0 \%, 20 \%, 40 \%, 60 \%, 80 \%$, and $100 \%$ by weight) instead of natural fine aggregate (NFA) and/or natural coarse aggregate (NCA). Three SCC series were designed with a constant slump flow of $700 \pm 30 \mathrm{~mm}$, total binder content of $570 \mathrm{~kg} / \mathrm{m}^{3}$ and at water-to-binder (w/b) ratio of 0.35 . Moreover, fly ash (FA) was used in concrete mixtures at $20 \%$ of total binder content. Mechanical aspects such as compressive, splitting tensile, and net flexural strengths and modulus of elasticity of SCC were investigated and experimentally computed at 28 days of age. Moreover, failure characteristics of the concretes were also monitored via three-point bending test on the notched beams. The findings revealed that the mechanical properties as well as fracture parameters were adversely influenced by incorporating of WG cullet. However, highest reduction of compressive strength did not exceed $43 \%$ recorded at $100 \%$ WG replacement level. Concretes containing WG showed less brittle behavior than reference concrete at any content.
\end{abstract}

\section{Introduction}

Turkey as one of the economically promising and developing countries has well operated waste management applications with over 2,000 scattered open dump areas. At the end of 2014, the manufacturers were responsible for collecting and recycling at least $60 \%$ of solid waste [1]. However, every year the amount of waste and its consequent disposal problems increased due to the increase in the standards of living, industrialization, and thus population. Moreover, among 25 million tonnes, about 17.5 million tonnes was disposed without any control [2]. Hence, waste recycling is deemed as the most suitable solution because it decreases the pollution of the nature and also helps to reuse energy production procedure. Glass waste is undesirable to disposal because it is nonbiodegradable which makes it environmentally less friendly; besides that the landfill capacity is being exhausted [3].
Thus, discarded waste glass (WG) has become a substantial burden on the landfills throughout the world. The challenge of disposal of waste glass continues to increase whenever the amount of waste glass increases and decreasing the capacity of landfill space [4]. In general, not all the waste glasses are suitable to be remelted and used to make new products because of the color mixed glass and contamination by papers and other substances [5]. Therefore, it is essential to find a sustainable alternative to reuse and recycle this material. Glass is a unique inert and ideal material which could be reused too many times without any change in its chemical properties [6]. Concrete construction provides a significant market potential for waste glass recycling via decreasing the cost of concrete [3]. In the past decade, the increase of disposal costs and legislating environmental regulations encouraged several researchers to investigate again the use of glass as concrete aggregates. Hence, Kou and Poon [5] prepared SCC 
with recycled glass aggregate. The authors investigated the fresh and mechanical properties and found that it was feasible to produce SCC with WG cullet until 30\% replacement level. Afshoon and Sharifi [7] also concluded that WG cullet could be successfully used for producing SCC. In similar way, Sharifi et al., 2013 [8], claimed that WG cullet as fine aggregate can be used to produce SCC in a standard manner. The author's results showed that there was no remarkable reduction in the strengths at 30\% replacement ratios of WG and less. Likewise, Meyer et al. [9] emphasized that it was practically feasible to produce SCC by using full replacement level of WG cullet as aggregates beside a suitable amount of fly ash (FA) and superplasticizer (SP). Asokan et al. [10] added $5-50 \%$ glass fiber reinforced plastic waste to concrete and tested the compressive strength. The results indicated that the compressive strength varied from 19 to $37 \mathrm{MPa}$ for concrete containing 50 to 5\%, respectively. Furthermore, Özkan and Yüksel [11] utilized different percentages of WG to investigate the mechanical and durability properties of cement-based mortars. The results revealed that the decrease in strength at $30 \%$ replacement level was tolerable and the durability properties were also valid.

As for mechanical and strength aspects, WG cullet concrete was expected to be inferior to conventional concrete. Indeed, these parameters were essentially controlled by the interlocking bond between cement and aggregate as well as the strength of interfacial transition zone (ITZ). Hence, replacing the rough surface of NA by a smooth one for crushed glass particles necessarily led to drop in strength; also, further reduction of an already low ductility is expected for this concrete [9]. In this regard, several previous literatures $[3,5,7,12]$ emphasized that the compressive strength as well as other mechanical properties were adversely effected by the addition of WG cullet. Conversely, Sangha et al. [13] reported that WG concrete showed higher compressive strength value as compared with conventional concrete. The authors noticed an increase in the value of compressive strength at $10 \%, 40 \%$, and $60 \%$ of green glass replacement levels.

The main problem in glass concrete is related to alkalisilica reaction (ASR), which was the major concern that thwarted the use of WG cullet in construction sectors [4, 1416]. The chemical reaction occurring between abundant silica in glass particles and the alkali in pore solution of concrete was not well understood decades ago [9]. Although it is believed that ASR process causes volume expansion which leads to cracks, however, this reaction is not restricted for glass aggregates only. Indeed, natural aggregate (NA) such as strained quartz and opaline chert contains certain amount of silica which can cause the same problem. Furthermore, reliable test methods are needed to predict the potential reactivity of NA because this reaction takes years to manifest itself. Hence, glass is deemed as an ideal aggregate to investigate ASR phenomenon in order to mitigate its detrimental results [17]. In this regard, studies are carried out to suppress the ASR expansion in concrete and to find methods for minimizing its effects. Lam et al. [18] and others [3, 6, 14] reported that the incorporating of suitable pozzolanic materials such as FA, ground blast furnace slag (GBFS), or metakaolin
(MK) in concrete mixtures can prevent and suppress this chemical action. Furthermore, Shi, 2009 [16] indicated that the expansion of concrete caused by traditional alkali-silica reaction was different from that of concrete containing glass aggregates. The author emphasized that WG concrete expanded when the moisture was present and when $\mathrm{pH}$ of the pore solution was greater than 12 .

In spite the fact that several previous literatures investigated the effect of WG cullet (as fine and/or coarse grade) on the properties of concrete, but the fracture parameters of WG concrete have not been examined yet. Moreover, most of conducted studies not only avoid using extreme replacement levels of WG cullet but also tested only one grade of WG aggregate (fine or coarse) $[5,7,8,19]$. In the present study, fracture properties of SCC as well as strength properties were inquired for multiple replacement levels of WG aggregate (as fine and/or coarse grade). Aside from control mix (CTR), three SCC series were designed with WG replacement levels of $0 \%, 20 \%, 40 \%, 60 \%, 80 \%$, and $100 \%$ by weight of NA. Constant w/b ratio of 0.35 and total binder content of $570 \mathrm{~kg} / \mathrm{m}^{3}$ were applied to produce 16 SCC mixtures. Moreover, FA was utilized in these concretes at $20 \%$ of total binder content to suppress the ASR reaction. In this study, the strength characteristics of concrete were conducted in the term of compressive, splitting tensile, net flexural strengths, and static modulus of elasticity. Moreover, fracture parameters tested in this study were fracture energy $\left(G_{F}\right)$ and characteristic length $\left(l_{\mathrm{ch}}\right)$. All aforementioned tests had been performed at 28 days and the results were evaluated and compared statistically.

\section{Experimental Program}

2.1. Materials. In this study, Portland cement used in all SCC mixtures was ordinary cement named CEM I $42.5 \mathrm{R}$ and identical to the Turkish specifications TS EN 197 [20] which are fundamentally derived from the European EN 197-1. Moreover, FA was utilized in concrete as replacement material by weight of cement at $20 \%$ level. The chemical and physical characteristics of cement, FA, and glass are listed in Table 1. The physical properties of WG cullet and NA were determined according to ASTM C127 [21]. In this regard, with specific gravity of 1.07, SP was employed to obtain the desired workability.

WG cullet was used at different replacement levels by weight of NA. In this regard, fine grade waste glass aggregate (WGFA) had a particle size of $0-4 \mathrm{~mm}$ and specific gravity of 2.53 , while coarse waste glass aggregate (WGCA) was utilized with a particle size of $4-11.2 \mathrm{~mm}$ and specific gravity of 2.55 (Figure 1). In effect, 24-hour absorption capacity of WG was too little and it could be neglected. Moreover, river sand type natural coarse aggregate (NCA) and natural fine aggregate (NFA) conforming to the TS 706 EN 12620-A1 [22] were used. The maximum sizes of NCA and NFA were 16 and $4 \mathrm{~mm}$ while 24 -hour absorption capacities were $0.77 \%$ and $1.09 \%$ respectively. Moreover, the physical observation of WG had exhibited smooth surfaces, angular shape, and sharp edge. The physical characteristics and sieve analysis of the aggregates used in this study are demonstrated in Table 2. 

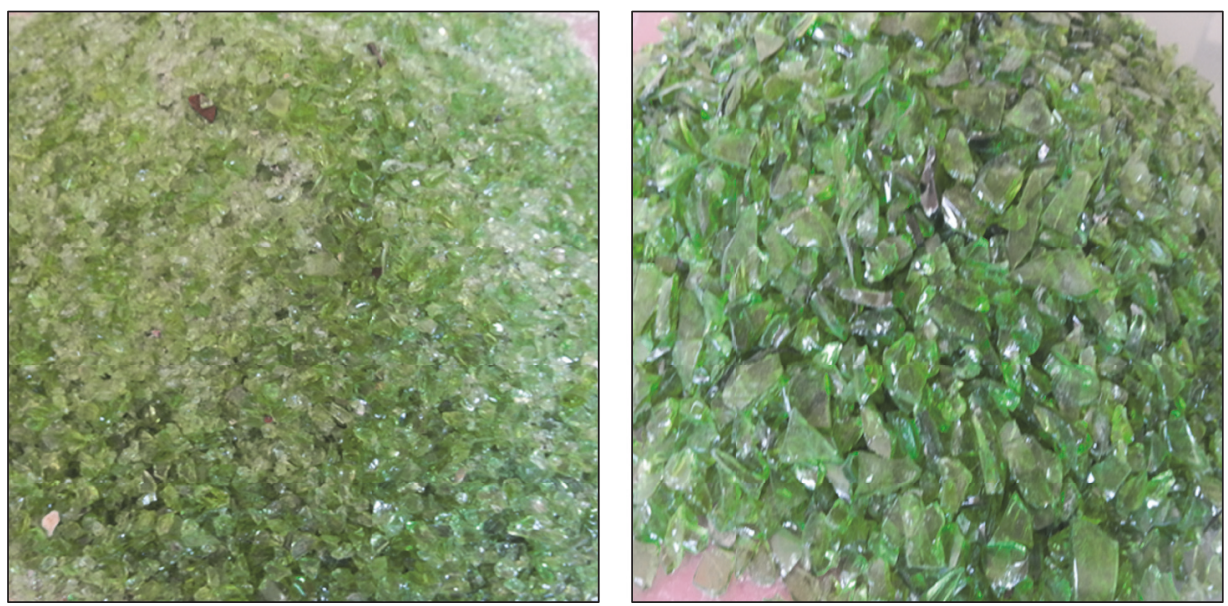

FIGURE 1: Fine and coarse grade of WG cullet.

TABle 1: Properties of cement and fly ash.

\begin{tabular}{lccc}
\hline Chemical analysis (\%) & Cement & Fly ash & Green glass \\
\hline $\mathrm{CaO}+\mathrm{MgO}$ & 67.06 & 4.64 & 15.60 \\
$\mathrm{SiO}_{2}$ & 19.79 & 57.2 & 71.91 \\
$\mathrm{Al}_{2} \mathrm{O}_{3}$ & 3.85 & 24.4 & - \\
$\mathrm{Fe}_{2} \mathrm{O}_{3}$ & 4.15 & 7.1 & 0.01 \\
$\mathrm{Cr}_{2} \mathrm{O}_{3}$ & - & - & 0.30 \\
$\mathrm{SO}_{3}$ & 2.75 & 0.29 & 0.22 \\
$\mathrm{~K}_{2} \mathrm{O}$ & - & 3.37 & 0.53 \\
$\mathrm{Na}_{2} \mathrm{O}$ & - & 0.38 & 9.58 \\
$\mathrm{TiO}_{2}$ & - & - & 0.06 \\
$\mathrm{SrO}$ & - & - & 0.01 \\
$\mathrm{P}_{2} \mathrm{O}_{5}$ & - & - & 0.06 \\
Other oxides & 2.40 & 2.62 & 1.72 \\
\hline Loss on ignition & 0.87 & 1.52 & - \\
Specific gravity & 3.15 & 2.04 & 2.55 \\
Specific surface area $\left(\mathrm{m}^{2} / \mathrm{kg}\right)$ & 326 & 379 & - \\
\hline
\end{tabular}

TABLE 2: Physical properties of natural and glass aggregates.

\begin{tabular}{lcccc}
\hline \multirow{2}{*}{ Sieve size $(\mathrm{mm})$} & \multicolumn{2}{c}{ Natural aggregate } & \multicolumn{2}{c}{ Glass aggregate } \\
& NFA & NCA & WGFA & WGCA \\
\hline 16 & 100 & 100 & 100 & 100 \\
8 & 100 & 30.40 & 100 & 24.10 \\
4 & 100 & 0 & 100 & 0 \\
2 & 58.13 & 0 & 51.57 & 0 \\
1 & 37.20 & 0 & 30.89 & 0 \\
0.5 & 24.24 & 0 & 10.63 & 0 \\
0.25 & 8.70 & 0 & 3.43 & 0 \\
0.125 & 0 & 0 & 0 & 0 \\
\hline Fineness modulus & 3.72 & 6.70 & 4.03 & 6.76 \\
Specific gravity & 2.39 & 2.69 & 2.53 & 2.55 \\
\hline
\end{tabular}

2.2. Mixture Proportioning and Sample Preparation. In addition to control mix (CTR) where NA were used as fine and coarse grade; 16 other concrete mixtures were designed and produced in a pan-type mixer with a $30 \mathrm{~L}$ capacity according to ASTM C192 [23]. SCC mixtures were subdivided into three series. In these mixtures, NA were replaced with WG cullet at replacement levels of $0 \%, 20 \%, 40 \%, 60,80$, and $100 \%$ by total volume of aggregate. In series I, NFA were replaced by fine grade WG cullet, while the mixtures in series II were made by replacing NCA with WGCA. Similarly in series III, concretes were incorporated with WG cullet for both coarse and fine grade. Thus, each series consisted of 5 mixtures according to replacement levels mentioned above. All concretes were prepared with a $570 \mathrm{~kg} / \mathrm{m}^{3}$ binder content and w/b ratio of 0.35 . In this regard and to suppress the potential alkali-silica reaction, FA was used in these concretes at $20 \%$ of total binder content. Moreover, to achieve the desired workability, different percentage of SP was utilized. As shown in Table 3, the concrete mixture codes were named basing on the mixture composition. For example, FWG0CWG0 indicated that SCC contained $0 \%$ WGFA and 0\% WGCA.

Concrete casting sequence started with mixing aggregate and/or WG cullet with the binder for one minute until it homogenized. Then, water containing SP was added in two parts to avoid segregation and the concretes were mixed for 3 minutes. Later, concrete was left for 2 minutes to rest and it was mixed again for an additional 2 minutes to complete the mixing sequence. For all concretes produced in this study, slump flow with diameter of $700 \pm 30 \mathrm{~mm}$ was assigned to meet the limitation of EFNARC [24]. For this, trial batches were conducted for each mixture until the target slump flow diameter was obtained.

\subsection{Test Procedure}

2.3.1. Strength and Modulus of Elasticity. In the current study, the compressive strength test was conducted according to the limitation of BS 1881-116 [25]. The results were computed by average of three cube specimens $(150 \times 150 \times 150 \mathrm{~mm})$ for each mix at 28 days. Similar to compressive test, splitting tensile strength also considered the average of three cylinder specimens $(100 \times 200)$ according to ASTM C496 [26], while 


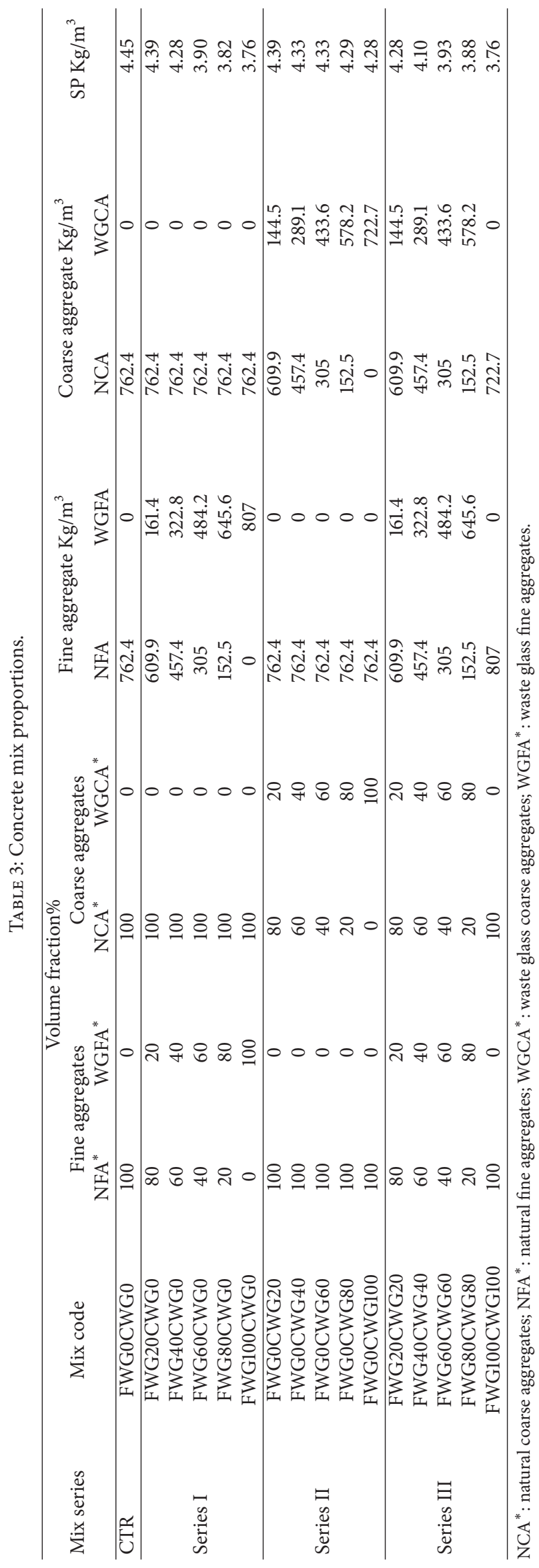




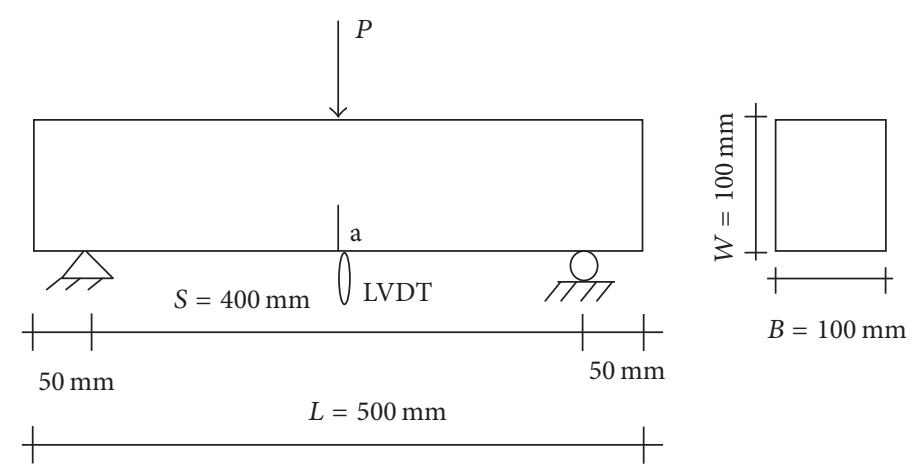

(a)

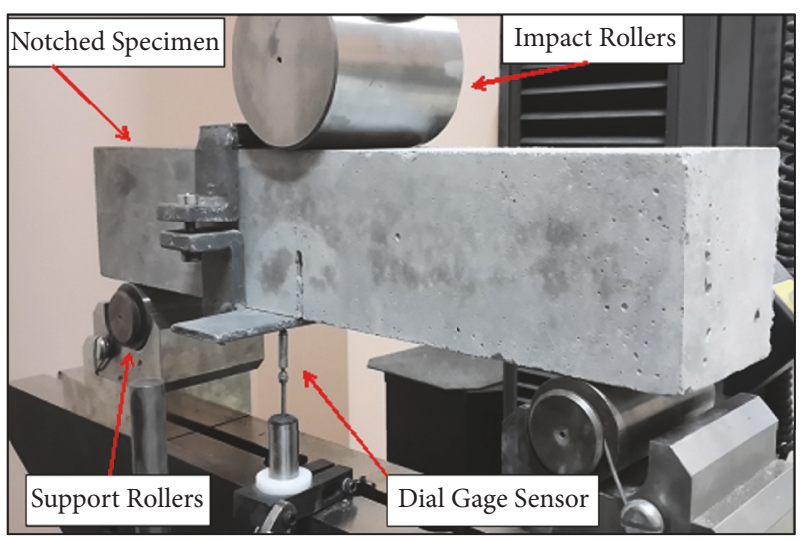

(b)

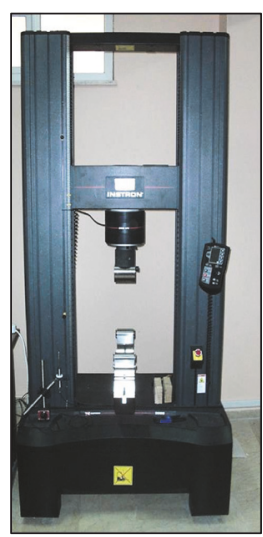

(c)

FIGURE 2: (a) Geometry of the three-point bending specimens used, (b) three-point testing schematic for flexural strength and fracture tests, and (c) test setup and specimen.

static modulus of elasticity was carried out with respect to BSI $1881-121$ [27]. In this test, $(150 \times 150 \times 150 \mathrm{~mm})$ cube specimens were employed to evaluate the elasticity of concrete. The specimen was subjected three times to $40 \%$ of maximum load, which was already specified through the results of compressive strength test. The values of modulus were measured by the average of the second two sets of readings whereas the first set was ignored for each cube. However, the average of at least three specimens was considered for each of abovementioned tests.

\subsubsection{Fracture Parameters. According to RILEM 50-FMC} [28], the work required to create one unit area of a crack is expressed as the fracture energy of materials. In cementitious materials, the fracture energy represents the indirect surface energy and it terms to the work of fracture [29]. Linear variable displacement transducer (LVDT) at midspan of samples was employed to measure the displacement simultaneously. As shown in Figure 2(a), a $500 \mathrm{~mm}$ in length with a cross section of $(100 \times 100)$ prism was employed to evaluate the fracture parameters. For this, closed-loop testing machine, Instron 5500R, was used to apply load with a maximum capacity of $250 \mathrm{kN}$ (Figure 2(b)). In the same regard, the overview of testing machine was depicted in Figure 2(c). In effect, $40 \mathrm{~mm}$ high notch was done via sawing the samples before testing. Thus, the ratio of notch to depth $(a / W)$ was considered at 0.4 . The fracture energy, in a single edge notched beams, was calculated via measuring the initial ligament area as well as the total dissipated energy. According to work of fracture (WFM) or Hillerborg's method, fracture energy, $G_{F}$, can be expressed as [30]

$$
G_{F}=\frac{W_{F}}{B(W-a)},
$$

where $W_{F}$ represents the total amount of WFM in the test, while the width and the initial notch depth of the beam are represented by $W$ and $a$, respectively. In the same regard, RILEM [28] proposed a similar relationship to describe the fracture energy of three-point bending test taking into consideration the effect of single edge notched beam. The equation can be written as

$$
G_{F}=\frac{W_{F}+m g \delta_{s}(S / U)}{B(W-a)},
$$

where the terms $m, g, \delta_{s}, S$, and $U$ denote mass, the acceleration due to gravity, the specified deflection, span, and length of the beam, respectively. Moreover, the net flexural strength, $f_{\text {flex }}$, can be theoretically calculated as follows using $(500 \times 100 \times 100 \mathrm{~mm})$ prism specimens used in fracture test:

$$
f_{\text {flex }}=\frac{3 P_{\max } S}{2 B(W-a)^{2}},
$$

in which $P_{\max }$ is the ultimate load. 


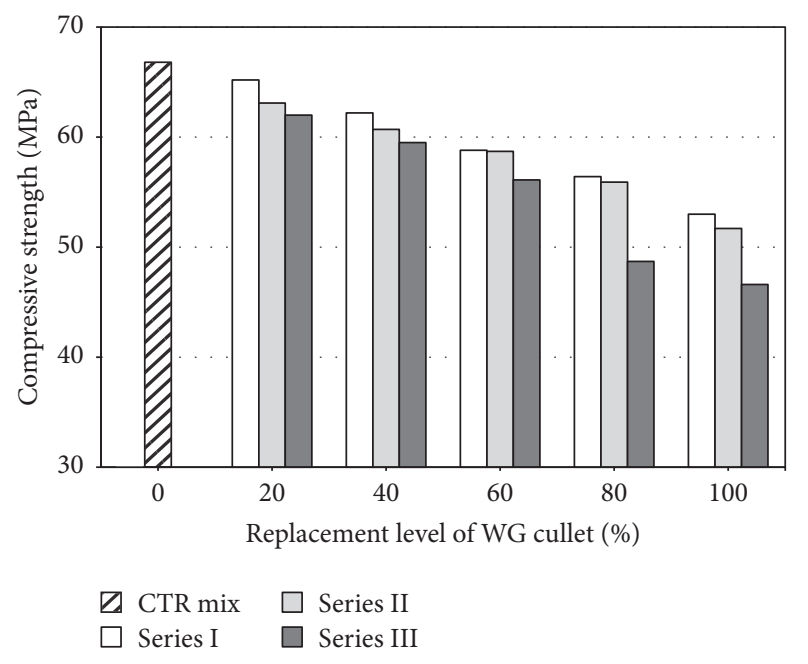

FIgURE 3: Compressive strength of SCC mixtures at 28 days with respect to WG cullet content.

In this regard, Hillerborg [29] described the brittleness of a material in WFM method through employing the fracture process zone length, which is related to the characteristic length parameter, as

$$
l_{\mathrm{ch}}=\frac{E G_{F}}{f_{\mathrm{st}}^{2}},
$$

where $E, G_{F}$, and $f_{\text {st }}$ are the static modulus of elasticity, the fracture energy, and splitting tensile strength of the beam, respectively.

\section{Results and Discussion}

3.1. Strength Properties. The 28-day compressive test results of concretes are demonstrated in Figure 3 in accordance with the replacement levels of WG cullet. It could be argued that the presence of WG as a full or partial replacement for NA inversely affected on the values of compressive strength. As shown in Figure 4, the concretes with 100\% WG replacement level revealed the highest reduction in strength. The corresponding reduction in the strength was in the range of $26 \%, 29 \%$, and $43 \%$ for series I, II, and III, respectively, as compared with CTR mixture; also, the values of compressive strength were in the range of 53.0-65.2, 51.7-63.1, and 46.6-62.0 MPa, respectively. In series III, where mixtures were made of WGFA and WGCA, the lowest values of compressive strength were observed. However, the reduction in compressive strength was deemed as consistent with previous literatures $[3,5,8,9,12,14]$, except at high replacement level of series III where the reduction trend was more pronounced. Hence, the range of compressive strength was acceptable for various uses of structural concrete (between 46.6 and 65.2 MPa).

In effect, the declining crushing strength of WG cullet is the main factor affecting on the strength of the produced SCC. This behavior attributes to the properties of glass which make it fragile when it is subjected to stress. Likewise, the

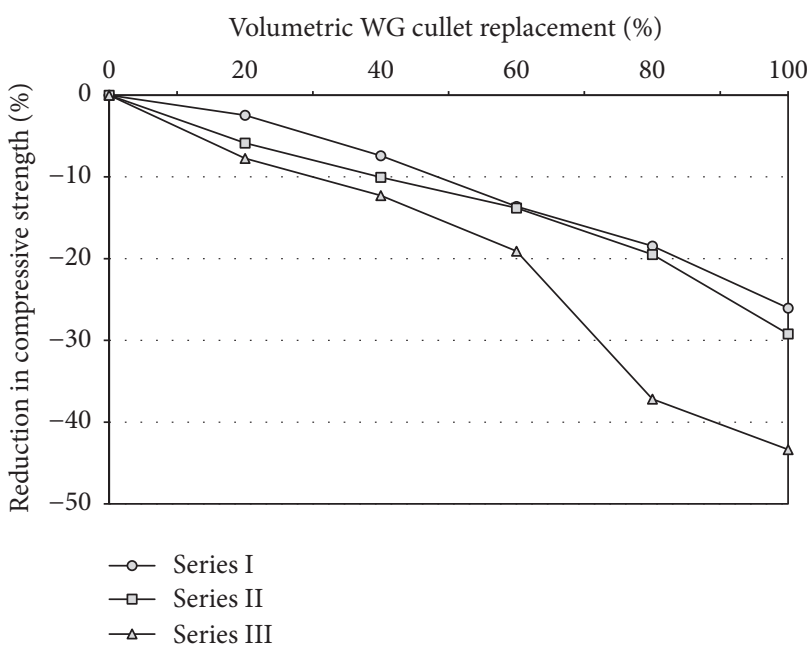

Figure 4: The reduction in compressive strength according to the content of WG cullet content.

high brittleness and poor geometry of glass aggregates lead to cracks which affect the adhesion between the glass particles and the cement paste. Indeed, the smooth surfaces and irregular particles shape weaken the mechanical interlocking [17]. Thus, WG cullet creates weak areas inside concrete matrix as well as weak ITZ strength leading to lower concrete strengths. Moreover, the microstructure of glass concrete contains more voids than conventional concrete due to the insufficient cement paste available inside the matrix which in turn adversely affects the bonding between concrete components [31].

Beside the smooth surface of the WG particles, the free water which is not absorbed by glass particles could accumulate at the surface of glass granules; leading to decrease in the strength of ITZ due to forming weak bond between them and cement paste. In the study of Tan and Du [30], it was emphasized that the weak bond strength between glass particles and cement paste dominated the strength of ITZ. According to author's point of view, sharp edges and smooth surface of WG particles were responsible for the weakness of ITZ strength. In this regard, Lam [32] believed that the reduction in the compressive strength of the WG cullet masonry was related to the fineness modulus of aggregates where the most suitable particle size ranged from 3.5 to 4.5.

The results of 28-day splitting tensile and net flexural strengths of SCC are depicted in Figures 5 and 6, respectively. The WG concretes manifested splitting tensile strengths ranging between 3.33 and 4.59, 2.78 and 4.41, and 2.23 and 4.07 MPa for the first, second, and third series, respectively, as compared with $5.03 \mathrm{MPa}$ recorded for CTR mixture. Obviously, the utilizing of WG cullet led to a decrease in tensile strength values depending on the level of replacement. Indeed, the reduction trend was more pronounced at high levels of glass replacement and in series III where glass was used as fine and coarse grade. For instant, the reduction in tensile strength was $33.8,44.7$, and $55.6 \%$ for series I, II, and III, respectively, compared with CTR mix. Similarly, flexural strength value followed the same decreasing trend observed 


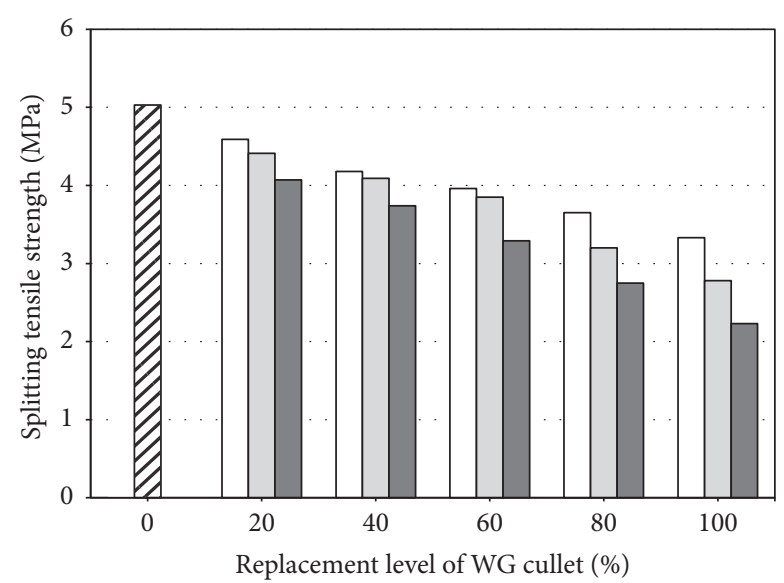

$\begin{array}{ll}\square \text { CTR mix } & \square \text { Series II } \\ \square \text { Series I } & \square \text { Series III }\end{array}$

FIGURE 5: Splitting tensile strength of SCC mixtures at 28 days with respect to WG cullet content.

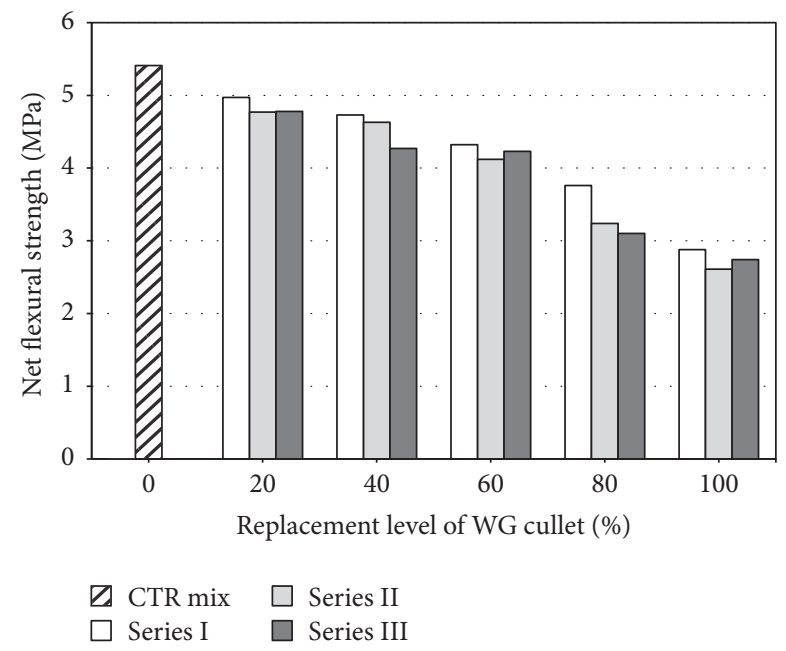

FIGURE 6: Net Flexural strength of SCC mixtures at 28 days with respect to WG cullet content.

for tensile strength. Indeed, as the WG cullet replacement level increased, the flexural as well as tensile strength of concretes decreased, compatible with previous authors results $[3,5,8]$. However, Sharifi et al., 2013 [8], reported that, at low replacement levels, fine grade of NA and WG cullet results in more adhesion between the glass particles and cement paste, producing more flexural and tensile strength values. In this study, flexural strength of SCC was in the range of 2.88-4.97, 2.61-4.77, and 2.74-4.78 MPa for the first, second, and third series, respectively, compared with $5.41 \mathrm{MPa}$ recorded for CTR mixture. In other words, full replacement level of WG resulted in a decrease in strength by $46.7 \%, 51.7 \%$, and $49.3 \%$ for series I, II, and III, respectively.

In effect, the low tensile strength of WG concrete induces rapid spread of microcracks under the applied load; then the concrete fails under lower load than conventional. Moreover, the factors and reasons responsible for decreasing the value
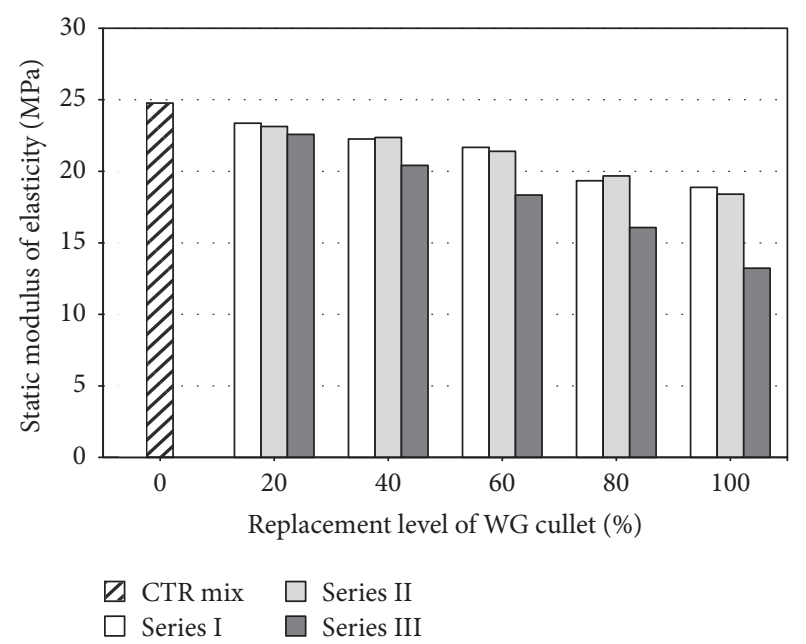

FIgURE 7: Modulus of elasticity of SCC mixtures at 28 days with respect to WG cullet content.

of compressive strength are the same in tensile and flexural strength. The fragile, smooth surface, sharp edges, and other physical properties again reduce the adhesion between the concrete components and thus negatively affect the strength of WG concretes. Moreover, the decrease in strengths might be due to the increase of porosity resulted by utilizing WG cullet as well as abundant mixing water. The tiny absorption capacity increases the availability of such water inside the concrete matrix contributing to the increase of porosity after it evaporates. Kou et al. [33] mentioned that free water would accumulate at the surface of particles due to smooth surface and insufficient water absorption of glass. Roberts [34] and others $[3,5,12,17,30,31]$ agreed with abovementioned point of view and reported similar trends.

The 28-day static modulus of elasticity for WG concretes is shown in Figure 7. The static moduli of SCC varied from 23.37 to $18.88,23.14$ to 18.4 , and 22.58 to $13.22 \mathrm{GPa}$ for series I, II, and III, respectively. These values could be compared with the corresponding value of $24.77 \mathrm{GPa}$ for CTR mix. The type of aggregate significantly affected on the elasticity of concrete via the elastic deformation of such aggregate which partially impacted the deformation of concrete. Hence, replacing NA by WG cullet decreased the modulus results particularly at high levels. For example, using $100 \%$ WG cullet caused a drop in the value of modulus by $23.7 \%, 25.7 \%$, and $46.6 \%$ for the first, second, and third series of SCC. Although the elastic modulus of WG cullet is higher than NA, the cellular microstructure at ITZ region and the weak interlocking in WG concrete cause microcracking inside the concrete structure, leading to lower modulus value than equivalent reference concrete. However, the effect of glass on modulus property of concrete is deemed as the least affected attribute compared with other mechanical aspects [30]. Consistent with the previously reported, the generation of higher porosity due to availability of mixing water might also contribute to the lower elastic behavior.

In the current study, the variation of splitting tensile strength and modulus of elasticity with compressive strength 
TABLE 4: Fracture properties of PW concrete at 28 days.

\begin{tabular}{|c|c|c|c|c|c|}
\hline Mix series & Mix code & $P_{\max }(\mathrm{N})$ & Final disp. at mid-span $\left(\delta_{s}\right)(\mathrm{mm})$ & Fracture energy $(\mathrm{N} / \mathrm{m})$ & Characteristic length (mm) \\
\hline CTR & FWG0CWG0 & 3244 & 1.43 & 160.18 & 156.82 \\
\hline \multirow{5}{*}{ Series I } & FWG20CWG0 & 2985 & 1.50 & 155.67 & 172.68 \\
\hline & FWG40CWG0 & 2836 & 1.50 & 142.85 & 181.91 \\
\hline & FWG60CWG0 & 2591 & 1.50 & 135.12 & 186.72 \\
\hline & FWG80CWG0 & 2256 & 1.50 & 129.82 & 188.46 \\
\hline & FWG100CWG0 & 1729 & 1.11 & 116.06 & 197.6 \\
\hline \multirow{5}{*}{ Series II } & FWG0RCG20 & 2863 & 1.50 & 145.69 & 173.35 \\
\hline & FWG0CWG40 & 2780 & 1.50 & 133.68 & 178.69 \\
\hline & FWG0CWG60 & 2473 & 1.50 & 128.9 & 186.01 \\
\hline & FWG0CWG80 & 1945 & 1.21 & 100.52 & 193.09 \\
\hline & FWG0CWG100 & 1563 & 1.14 & 85.12 & 202.66 \\
\hline \multirow{5}{*}{ Series III } & FWG20CWG20 & 2871 & 1.39 & 132.27 & 180.3 \\
\hline & FWG40CWG40 & 2563 & 1.50 & 128.37 & 187.4 \\
\hline & FWG60CWG60 & 2540 & 1.11 & 117.55 & 199.17 \\
\hline & FWG80CWG80 & 1862 & 1.15 & 95.84 & 203.53 \\
\hline & FWG100CWG100 & 1646 & 0.77 & 79.26 & 210.71 \\
\hline
\end{tabular}

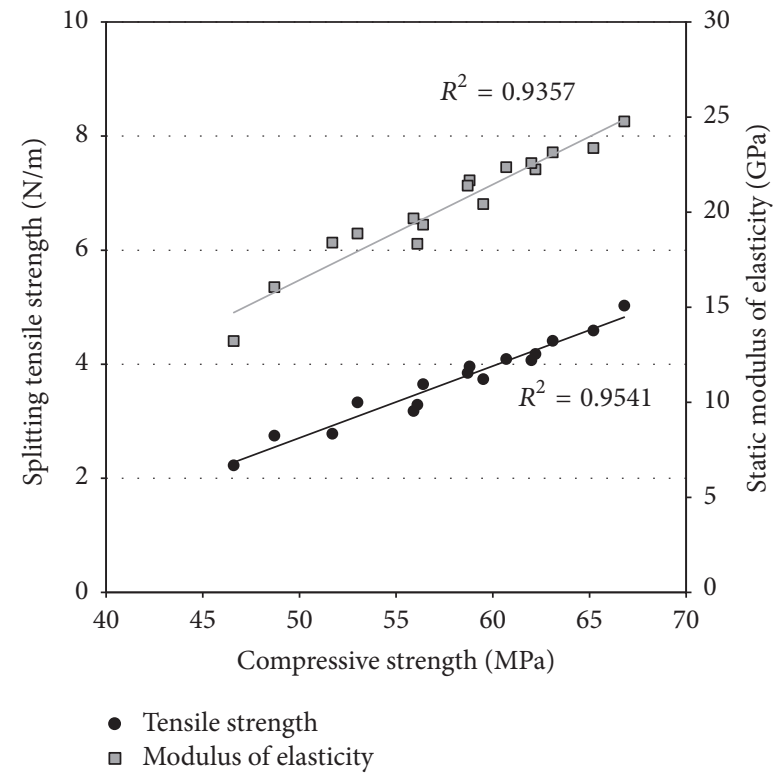

FIGURE 8: Splitting tensile strength and modulus of elasticity of SCC versus compressive strength.

are depicted in Figure 8. In this figure, an excellent correlation could be drawn between these parameters particularly with compressive strength of WG concretes. In this regard, Kou et al. [33] also found similar linear relationship for these parameters with the compressive strength, while Choi et al. [35] preferred to express this relationship via power equation with (1/3) exponent coefficient. Kou and Poon [5] observed good correlation between these parameters and drew a power relationship between compressive strength and modulus of elasticity for SCC mixtures. Hence, linear relationship between tensile and compressive strength by means of regression analysis could be employed via the results of this study. Moreover, the linear equation below with correlation coefficient $\left(R^{2}\right)$ of 0.95 can describe this relationship:

$$
f_{\mathrm{st}}=0.12 f_{c}-3.58 .
$$

Furthermore, the below equation expresses the relationship between static modulus of elasticity and compressive strength with $R^{2}$ of 0.93 :

$$
E_{c}=0.5 f_{c}-8.7,
$$

where $f_{\text {st }}, E_{c}$, and $f_{c}$ represent tensile strength, the modulus of elasticity, and the compressive strength of SCC, respectively. Indeed, the correlation factor, $R^{2}$, of equation above revealed that compressive strength of concretes was well correlated with the other mechanical parameters despite the different replacement levels of WG.

3.2. Fracture Characteristics. The fracture parameter results of glass SCC tested in this study are summarized in Table 4 and graphically depicted in Figure 9, in which mix FWG0CWG0 represents the control mix of the present study. In effect, the presence of WG cullet at any percentage causes a discrete reduction in maximum load value $\left(P_{\max }\right)$ recorded for concretes. In the load-displacement curve, the prepeak stiffness was considerably affected by incorporating WG in concrete. Hence, the highest value of peak load was recorded in CTR mixture at $3244 \mathrm{~N}$; then it continuously decreased depending on the replacement levels and the grade of WG used in the concretes. The lowest values were observed for $100 \%$ replacement level of WG cullet. They were recorded as 1726,1563 , and $1646 \mathrm{~N}$, for first, second, and third series. As shown in Figure 9, as WG cullet was incorporated in concretes, a trend of decreasing could be noted. For instance, in series $\mathrm{I}$, the reduction in recorded $P_{\max }$ was $8 \%, 12.6 \%$, $20.1 \%, 30.5 \%$, and $46.7 \%$ for $20 \%, 40 \%, 60 \%, 80 \%$, and 


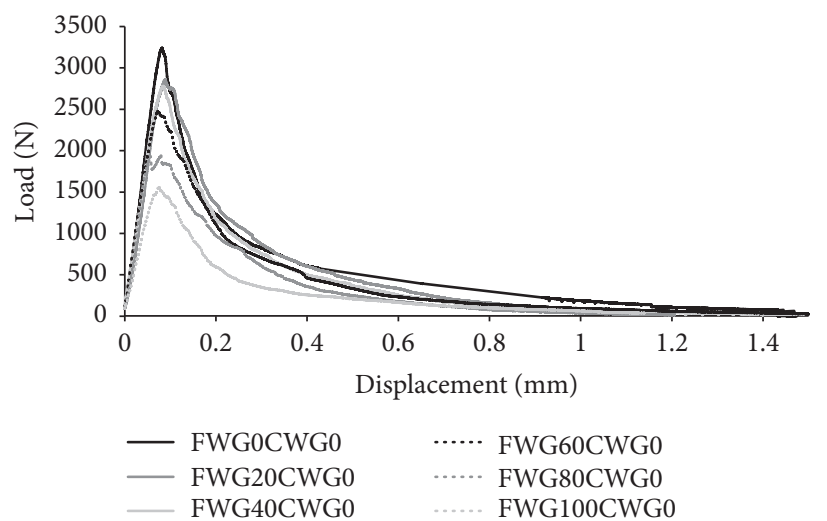

(a)

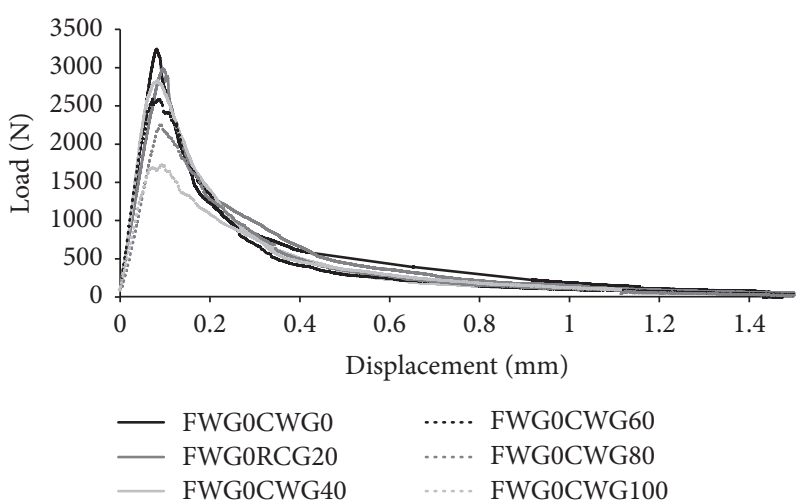

(b)
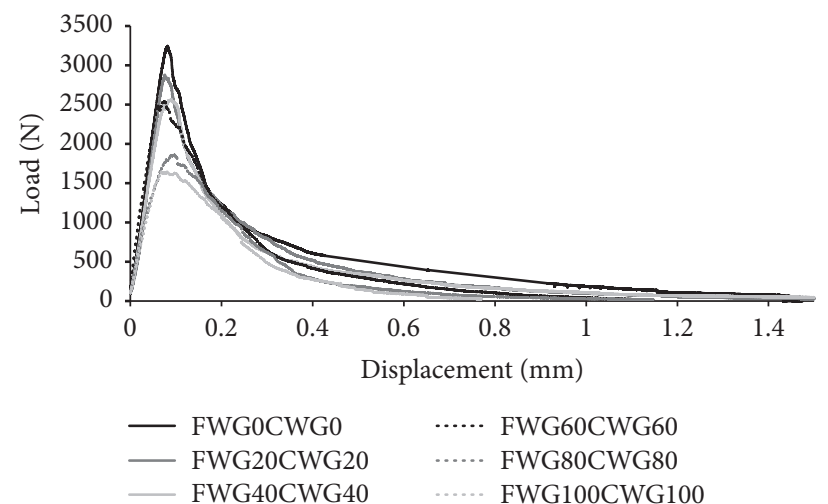

(c)

Figure 9: Load versus displacement curve of (a) WGFAs (series I), (b) WGCAs (series II), and (c) WGFAs + WGCAs (series III).

$100 \%$ replacement levels, respectively. Hence, it could be estimated that the peak load noticeably depended on the glass content inside the mixture. However, $P_{\max }$ values represent the highest bearing load which the samples can carry before the cracks appear which in turn are controlled by the strength properties of concrete. In effect, the prepeak and max-peak performances in load-displacement curve are affected by the microcracks and their extension in concrete. In WG concrete, cracks can more easily penetrate through the matrix than conventional concrete due to few amounts of stiffer NA $[36,37]$. The physical properties as well as inferior strength of glass aggregate compared with NA contribute to the decrease in peak load. In the present study, most mixtures revealed extended final displacement even for WG concrete. Indeed, the variation in the tail of the softening branch referred to higher elastic behavior of concrete except at highest levels of series II and III, in which it showed higher brittle performance than other mixtures.

The variations of fracture energy $\left(G_{F}\right)$, the energy required to create a crack, are illustrated in Figure 10 and tabulated in Table 4 . The value of fracture energy for CTR mix recorded $160.2 \mathrm{~N} / \mathrm{m}$ and gradually reduced until it reached to the range of $116.1-155.7,85.1-145.7$, and $79.3-132.3 \mathrm{~N} / \mathrm{m}$ for series I, II, and III, respectively. In effect, the extreme reduction could be observed at $100 \%$ replacement level in each series. It recorded $27.5 \%, 46.8 \%$, and $50.5 \%$ for the first, second, and third series, respectively, compared with

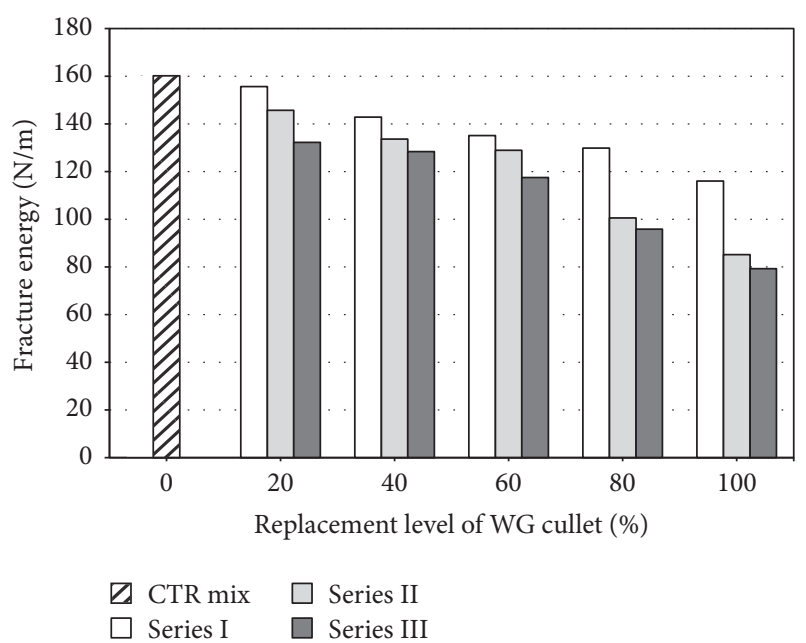

FIGURE 10: Fracture energy of SCC mixtures at 28 days with respect to WG cullet content.

CTR mixture. Previous publications emphasized that $G_{F}$ of concrete was related to the cement paste-aggregate interfacial bond and the microstructural heterogeneity in the concrete $[37,38]$. The utilization of WG in concrete resulted in high porosity, easy crack penetration, and weaker ITZ region than reference concrete. These factors adversely affected and 


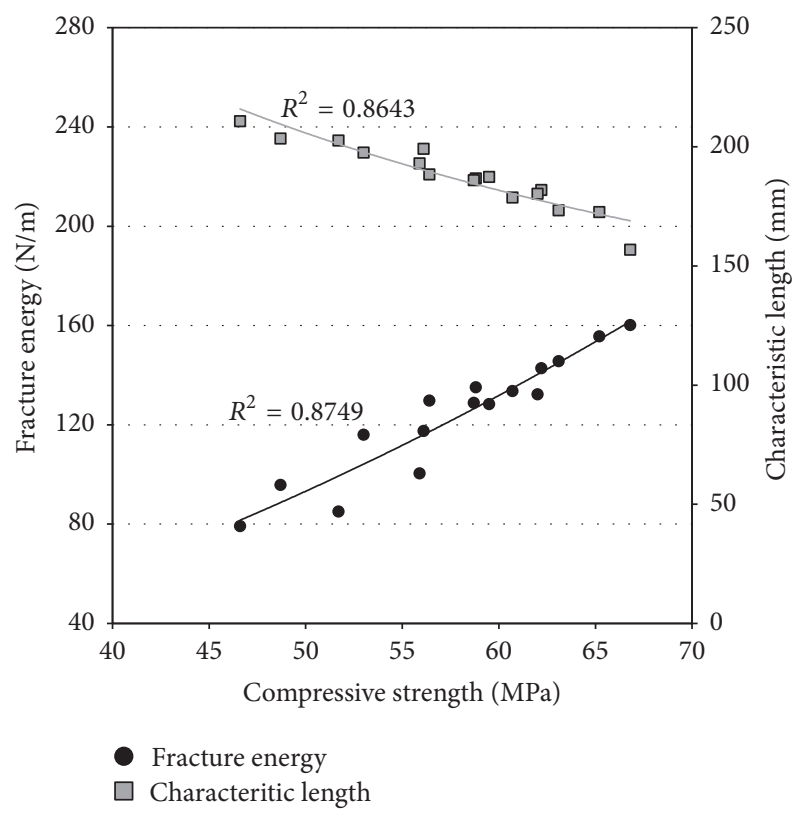

FIGURE 11: Fracture energy and characteristic length of SCCs versus compressive strength.

decreased the value of $G_{F}$ and hence denoted less brittle behavior.

Fracture parameters such as $G_{F}$ can be expressed as a function of compressive strength. According to CEB-FIB [39], fracture energy can be related with compressive strength in the form of power function. Moreover, various investigators have suggested a direct relationship between these parameters [40,41]. As shown in Figure 11, fracture energy was directly proportional with compressive strength and the relationship could be expressed via the power equation below, with correlation coefficient $\left(R^{2}\right)$ of 0.87 :

$$
G_{F}=0.055 f_{c}^{1.9}
$$

in which $G_{F}$ is the total fracture energy $(\mathrm{N} / \mathrm{m})$ and $f_{c}$ is the mean cube compressive strength at 28 days (MPa).

The brittleness of SCC can be measured via employing (4) proposed by Hillerborg [29]. In the present study, the results revealed that characteristic length $\left(l_{\mathrm{ch}}\right)$ computed from equation above gradually increased whenever WG replacing level increased. As depicted in Figure 12, the highest value of $l_{\mathrm{ch}}$ was recorded for $100 \%$ replacement level mixtures regardless of WG cullet grade. Indeed, the value of $l_{\mathrm{ch}}$ increased by $20.6 \%, 22.6 \%$, and $25.5 \%$ for mixtures FWG100CWG0, FWG0CWG100, and FWG100CWG100, respectively, which represented the highest value for each series (Table 4). These findings emphasized that WG cullet concrete was less brittle than reference mixture due to the fact that the glass had an adverse effect on the strength of concrete. The inferior bond strength between glass particles and cement paste, which degrades the ITZ of such concrete, produces an increase in stress concentration around aggregates. Thus, cracks may develop through aggregates leading to contraction in fracture process zone and the concrete could have a more ductile

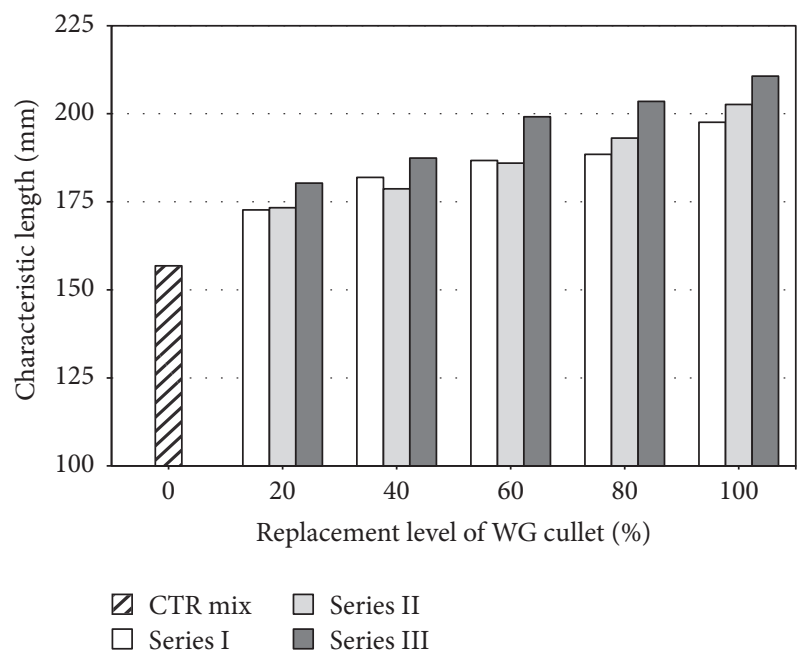

FIGURE 12: Characteristic length of SCC mixtures at 28 days with respect to WG cullet content.

behavior [42]. The weak paste-aggregate interface and nonhomogeneous microstructure in WG concrete are responsible for the reduction in the brittleness of such concrete. Hence, the crack pattern is different than reference concrete.

In effect, few publications that dealt with the effect of WG cullet on the fracture parameters were available. Due to the brittleness being strongly related to the strength properties of concrete, WG cullet concretes revealed high brittle behavior. Compared with reference, WG concrete had a higher brittle behavior. This behavior attributed to the presence of cracks in aggregate phase causing changes in concrete fractal dimensions. Indeed, the fragile nature of WG cullet (which made it easy to rupture under stress) also reinforced this performance. Moreover, the lowest fractal dimension and smoother fracture surface are observed when the failure path passes directly through the aggregates $[42,43]$.

In effect, the ductility index is controlled by the interlocking bond between cement aggregates which is deemed as weak in glass concrete. Hence, in this study lch revealed lower values whenever the strength increased in agreement with brittle behavior. Characteristic length could also be expressed as a function of compressive strength as shown in Figure 11. In spite of the difference in the mix proportions of concretes, a good correlation could be written below to describe the relationship between characteristic length and compressive strength with $R^{2}$ of 0.86 :

$$
l_{\mathrm{ch}}=2951 f_{c}^{-0.68},
$$

where $l_{\mathrm{ch}}$ is characteristic length $(\mathrm{mm})$ and $f_{c}$ is the mean cube compressive strength at 28 days ( $\mathrm{MPa})$.

\section{Conclusions}

(i) As WG cullet was incorporated and its content increased, the compressive strength values were negatively affected. However, among the three series of concretes, the reduction in strength did not exceed 
$26 \%$ and $29 \%$ for the first and second series, respectively, as compared to the corresponding reference mixtures. Except in series III, the decrease in strength became more pronounced with a maximum reduction of $43 \%$. However, the lowest compressive strength was $46.6 \mathrm{MPa}$ which was deemed acceptable for various uses of structural concrete.

(ii) Splitting tensile strength, net flexural strength, and modulus of elasticity findings followed the similar trend observed in compressive strength results, while the reduction in these parameters was more pronounced at high levels of WG replacement and in series III where the glass was used as fine and coarse grade.

(iii) Regardless of the replacement level of WG cullet, $P_{\max }$, area under the load-displacement curve and fracture energy values revealed minimal values whenever glass aggregate was present and its content increased. Conversely, characteristic length recorded higher values for WG concrete indicating less brittle behavior than reference concrete.

(iv) An excellent correlation between splitting tensile strength, modulus of elasticity, fracture energy, and characteristic length could be expressed as a function of the compressive strength. These relationships followed linear and power equations for mechanical and fracture parameters, respectively.

\section{Additional Points}

Highlights. Waste glass (WG) cullet was prepared through crushing green-colored glass bottles. WG cullet was used at different percentages. Self-compacting concretes (SCCs) were made with and/or without WG cullet. Strength properties of SCCs were adversely affected by the use of WG cullet. The uses of WG cullet resulted in lower fracture energy and higher values of characteristic length.

\section{Conflicts of Interest}

The authors declare that they have no conflicts of interest.

\section{References}

[1] Turkish Court of Accounts, Waste Management in Turkey, National Regulations and Evaluation of Implementation Results, Performance Audit Report, vol. 81, 2007.

[2] M. Berkun, E. Aras, and T. Anilan, "Solid waste management practices in Turkey," Journal of Material Cycles and Waste Management, vol. 13, no. 4, pp. 305-313, 2011.

[3] I. B. Topcu and M. Canbaz, "Properties of concrete containing waste glass," Cement and Concrete Research, vol. 34, no. 2, pp. 267-274, 2004.

[4] A. M. Rashad, "Recycled waste glass as fine aggregate replacement in cementitious materials based on Portland cement," Construction and Building Materials, vol. 72, pp. 340-357, 2014.

[5] S. C. Kou and C. S. Poon, "Properties of self-compacting concrete prepared with recycled glass aggregate," Cement and Concrete Composites, vol. 31, no. 2, pp. 107-113, 2009.
[6] A. Shayan, "Value-added utilisation of waste glass in concrete," in Proceedings of the IABSE Symposium, p. 11, ARRB Transport Research, Melbourne, Victoria, Australia, 2002.

[7] I. Afshoon and Y. Sharifi, "Ground copper slag as a supplementary cementing material and its influence on the fresh properties of self-consolidating concrete," IES Journal Part A: Civil and Structural Engineering, vol. 7, no. 4, pp. 229-242, 2014.

[8] Y. Sharifi, M. Houshiar, and B. Aghebati, "Recycled glass replacement as fine aggregate in self-compacting concrete," Frontiers of Structural and Civil Engineering, vol. 7, no. 4, pp. 419-428, 2013.

[9] C. Meyer, S. Baxter, and W. Jin, "Alkali-aggregate reaction in concrete with waste glass as aggregate," in Proceedings of 4th materials engineering, pp. 1388-1397, Reston, VA., ASCE, 1996.

[10] P. Asokan, M. Osmani, and A. D. F. Price, "Assessing the recycling potential of glass fibre reinforced plastic waste in concrete and cement composites," Journal of Cleaner Production, vol. 17, no. 9, pp. 821-829, 2009.

[11] Ö. Özkan and I. Yüksel, "Studies on mortars containing waste bottle glass and industrial by-products," Construction and Building Materials, vol. 22, no. 6, pp. 1288-1298, 2008.

[12] S. B. Park, B. C. Lee, and J. H. Kim, "Studies on mechanical properties of concrete containing waste glass aggregate," Cement and Concrete Research, vol. 34, no. 12, pp. 2181-2189, 2004.

[13] C. M. Sangha, A. M. Alani, and P. J. Walden, "Relative strength of green glass cullet concrete," Magazine of Concrete Research, vol. 56, no. 5, pp. 293-297, 2004.

[14] P. Turgut and E. Yahlizade, "Research into Concrete Blocks with Waste Glass," International Journal Civil, Environmental, Structural, Construction and Architectural Engineering, vol. 3, no. 3, 2009.

[15] Environmental Protection Department, Monitoring of solid waste in 2005, Environmental Protection Department, Hong Kong, 2006.

[16] C. Shi, "Corrosion of glasses and expansion mechanism of concrete containing waste glasses as aggregates," Journal of Materials in Civil Engineering, vol. 21, no. 10, pp. 529-534, 2009.

[17] C. Meyer, N. Egosi, and C. Andela, "Concrete with waste glass as aggregate," in Proceedings of the International Symposium Concrete Technology Unit of ASCE, 2001.

[18] C. S. Lam, C. S. Poon, and D. Chan, "Enhancing the performance of pre-cast concrete blocks by incorporating waste glass-ASR consideration," Cement and Concrete Composites, vol. 29, no. 8, pp. 616-625, 2007.

[19] E. E. Ali and S. H. Al-Tersawy, "Recycled glass as a partial replacement for fine aggregate in self compacting concrete," Construction and Building Materials, vol. 35, pp. 785-791, 2012.

[20] TS EN 197-1, Cement- Part 1: Composition, Specifications and Conformity Criteria for Common Cements, Turkish Standards, 2012.

[21] ASTM C 127, "Standard test method for specific gravity and absorption of coarse aggregate," in Annual Book of ASTM Standards, 2015.

[22] TS 706 EN 12620-A1, Aggregates for Concrete, Institute of Turkish Standards, Turkish Standards, 2012.

[23] ASTM C 192, "Standard practice for making and curing concrete test specimens in the laboratory," in Annual Book of ASTM Standards, 2015, Standard practice for making and curing concrete test specimens in the laboratory in.

[24] EFNARC, European Guidelines for Self-Compacting Concrete, Specification and Production and Use, Association House, 2005. 
[25] British Standard Institution, Part 116. BS 1881-116:1983, Testing Concrete Method for Determination of Compressive Strength of Concrete Cubes, BS 1881, BSI, London, 2004.

[26] ASTM C496, "Standard test method for splitting tensile strength of cylindrical concrete specimens. International standards worldwide," in Proceedings of the Annual book of ASTM standards, 2015.

[27] Part 121. Recommendations for the measurement of static modulus of elasticity. BS 1881, BSI, 2014.

[28] RILEM 50-FMC, "Committee of fracture mechanics of concrete. Determination of fracture energy of mortar and concrete by means of three-point bend tests on notched beams," Mater Struct, vol. 18, no. 106, pp. 285-290, 1985.

[29] A. Hillerborg, "Concrete fracture energy tests performed by 9 different laboratories according to a draft RILEM recommendation," Report to RILEM TC50- FMC. Report TVMB-3015, Lund Sweden, 1983.

[30] K. H. Tan and H. Du, "Use of waste glass as sand in mortar: part I - Fresh, mechanical and durability properties," Cement and Concrete Composites, vol. 35, no. 1, pp. 118-126, 2013.

[31] M. Adaway and Y. Wang, "Recycled glass as a partial replacement for fine aggregate in structural concrete -Effects on compressive strength," Electronic Journal of Structural Engineering, vol. 14, no. 1, pp. 116-122, 2015.

[32] C. Lam, Use of recycled construction and demolition wastes as aggregates in pre-cast block works [Msc. thesis], The Hong Kong Polytechnic University, Hong Kong, 2006.

[33] S. C. Kou, G. Lee, C. S. Poon, and W. L. Lai, "Properties of lightweight aggregate concrete prepared with PVC granules derived from scraped PVC pipes," Waste Management, vol. 29, no. 2, pp. 621-628, 2009.

[34] L. R. Roberts, Microsilica in concrete, materials science of concrete, American Ceramic Society, Westerville, Ohio, OH, USA, 1989.

[35] Y. W. Choi, D. J. Moon, Y. J. Kim, and M. Lachemi, "Characteristics of mortar and concrete containing fine aggregate manufactured from recycled waste polyethylene terephthalate bottles," Construction and Building Materials, vol. 23, no. 8, pp. 2829-2835, 2009.

[36] A. Bordelon, V. Cervantes, and J. R. Roesler, "Fracture properties of concrete containing recycled concrete aggregates," Magazine of Concrete Research, vol. 61, no. 9, pp. 665-670, 2009.

[37] M. Arezoumandi, J. Drury, J. S. Volz, and K. H. Khayat, "Effect of recycled concrete aggregate replacement level on shear strength of reinforced concrete beams," ACI Materials Journal, vol. 112, no. 4, pp. 559-568, 2015.

[38] C. Taşdemir, M. Taşdemir, F. Lydon, N. Mills, and B. Barr, "Combined effects of silica fume, aggregate type, and size on post-peak response of concrete in bending," ACI Materials Journal, vol. 96, no. 1, 1999.

[39] CEB-FIP Model Code 2010-Design Code, Thomas Telford House, London, 2010.

[40] C. Albano, N. Camacho, M. Hernández, A. Matheus, and A. Gutiérrez, "Influence of content and particle size of waste pet bottles on concrete behavior at different w/c ratios," Waste Management, vol. 29, no. 10, pp. 2707-2716, 2009.

[41] H. Eskandari, S. Muralidhara, B. K. Raghu Prasad, and B. V. Venkatarama Reddy, "Size effect in self consolidating concrete beams with and without notches," Sadhana-Academy Proceedings in Engineering Sciences, vol. 35, no. 3, pp. 303-317, 2010.
[42] M. H. A. Beygi, M. T. Kazemi, I. M. Nikbin, and J. V. Amiri, "The effect of water to cement ratio on fracture parameters and brittleness of self-compacting concrete," Materials \& Design, vol. 50, pp. 267-276, 2013.

[43] A. Yan, K.-R. Wu, D. Zhang, and W. Yao, "Effect of fracture path on the fracture energy of high-strength concrete," Cement and Concrete Research, vol. 31, no. 11, pp. 1601-1606, 2001. 

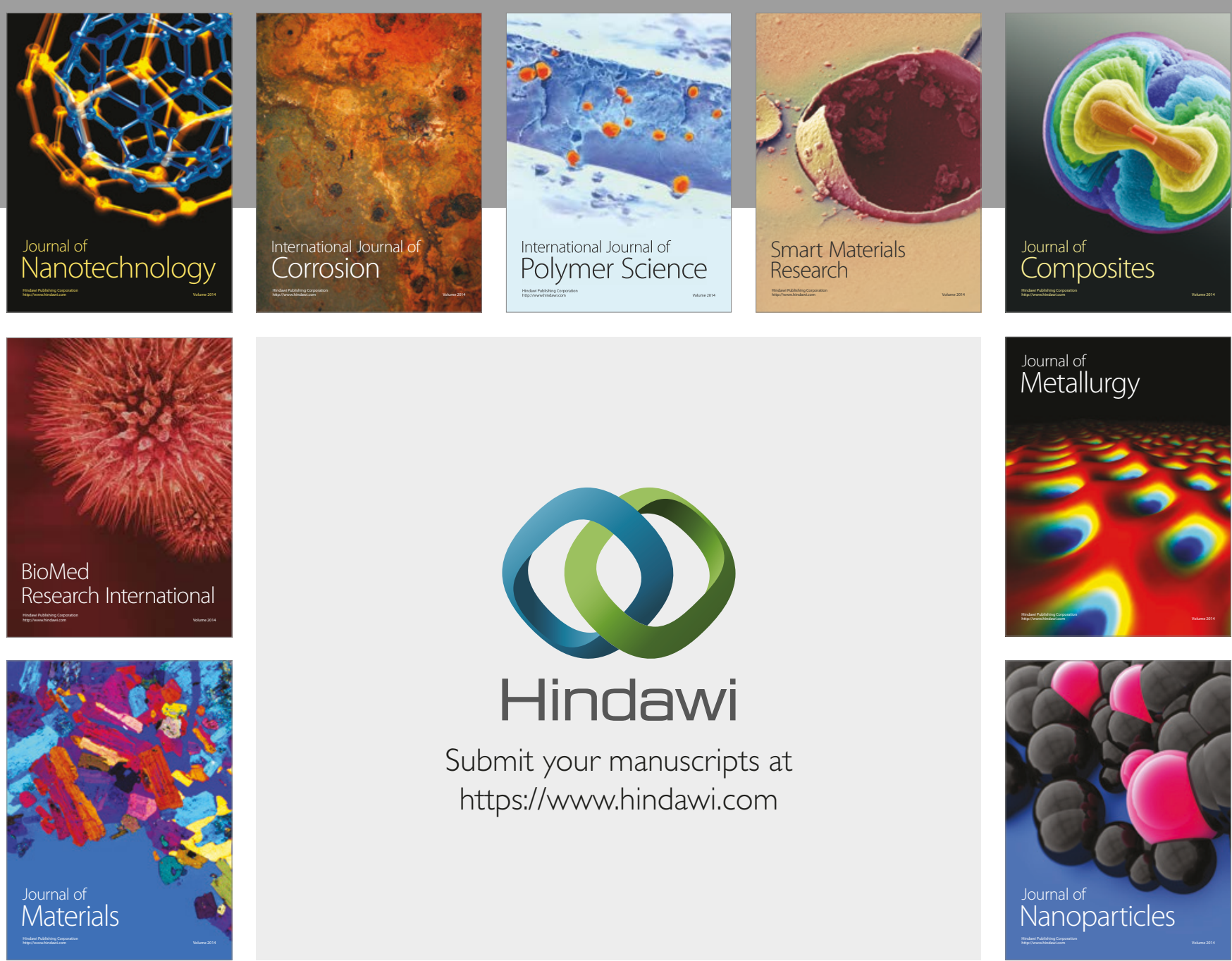

\section{Hindawi}

Submit your manuscripts at

https://www.hindawi.com
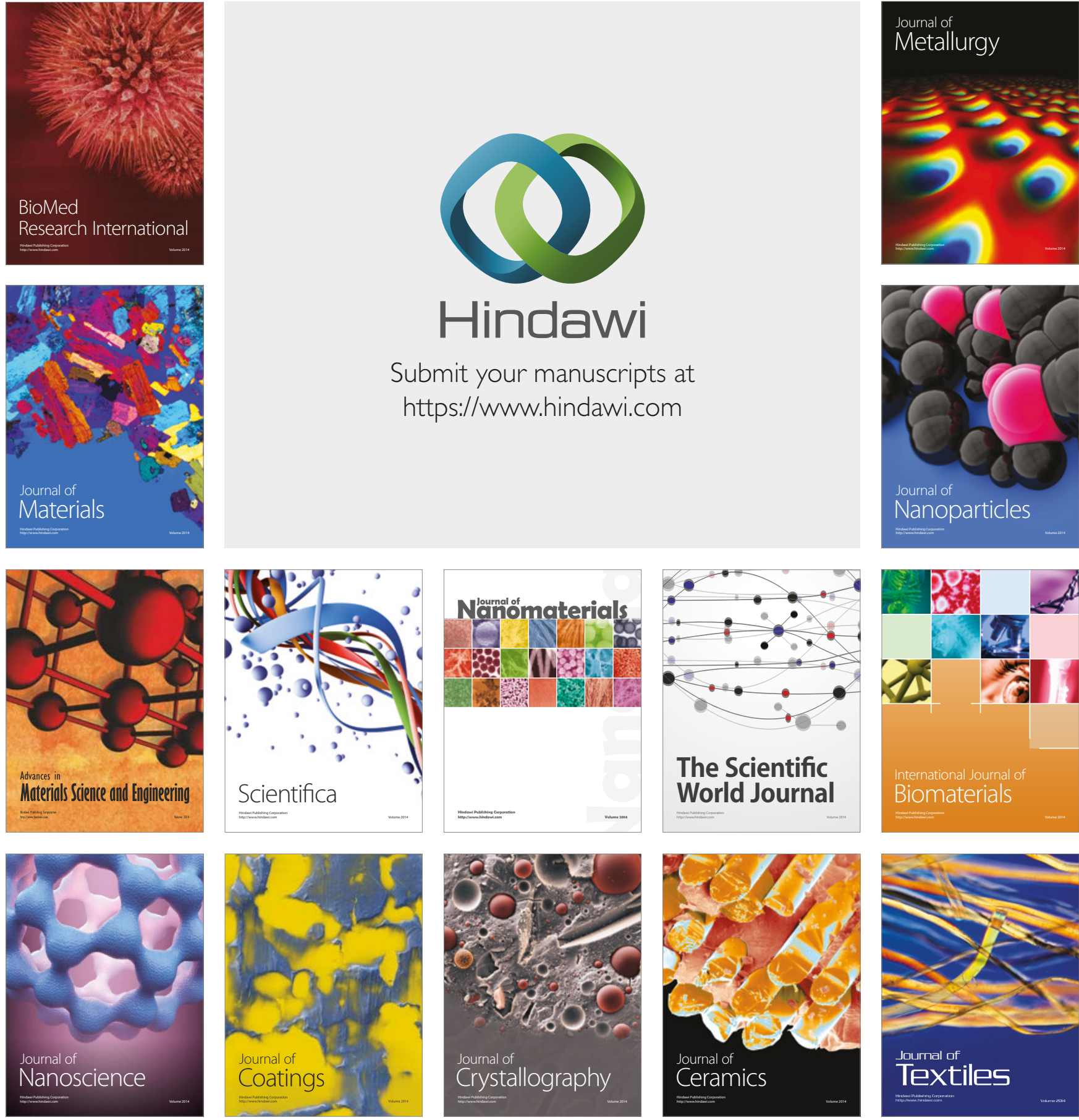

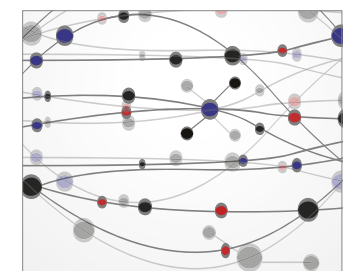

The Scientific World Journal
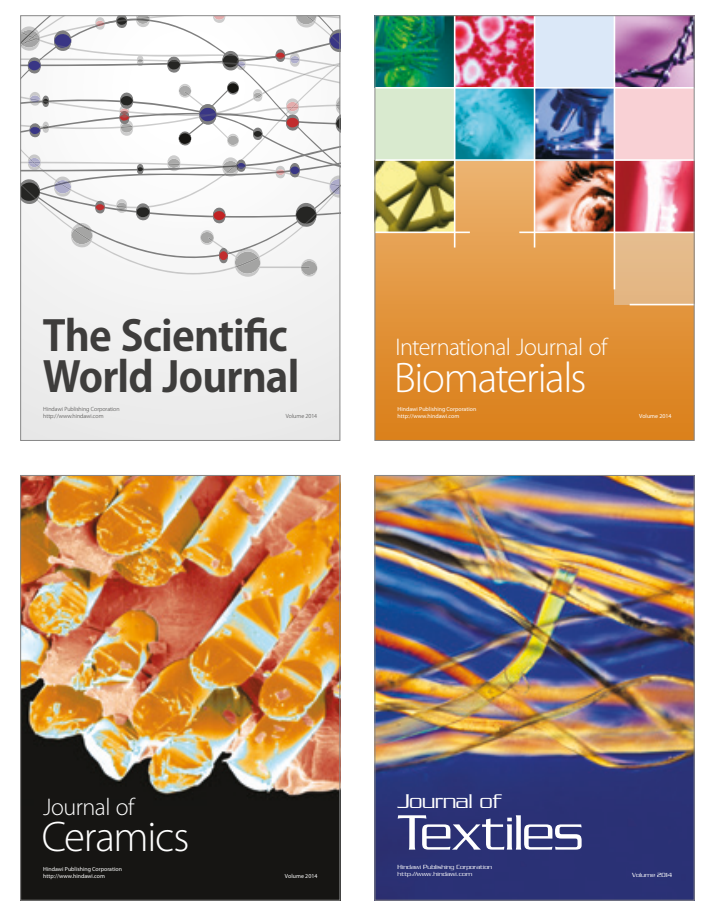